\title{
EFICIÊNCIA DO Bacillus thuringiensis var. kurstaki (Berliner, 1915) NO CONTROLE DA TRAÇA DA CERA Galleria mellonella (Linnaeus, 1758) (Lepidoptera: Pyralidae)
}

\author{
Efficiency of Bacillus thuringiensis var. kurstaki (Berliner, 1915) for control of the \\ greater wax moth Galleria mellonella (Linnaeus, 1758) (Lepidoptera: Pyralidae) \\ Deodoro Magno Brighenti ${ }^{1}$, César Freire Carvalho ${ }^{2}$, Geraldo Andrade Carvalho², \\ Carla Regina G. Brighenti ${ }^{3}$
}

\begin{abstract}
RESUMO
Objetivou-se avaliar a eficiência do Bacillus thuringiensis var. kurstaki (Berliner) no controle de Galleria mellonella (Linnaeus). Os experimentos foram realizados no Laboratório de Biologia de Insetos do Departamento de Entomologia da Universidade Federal de Lavras - UFLA, Lavras, MG, a $28 \pm 2^{\circ} \mathrm{C}$, UR $70 \pm 10 \%$ e fotofase de 12 horas. Aplicou-se formulação comercial de $B$. thuringiensis var. kurstaki por meio de pulverização, imersão dos favos e também foi incorporada à dieta artificial fornecida às lagartas de terceiro ínstar da traça da cera. A aplicação do produto fitossanitário por meio da pulverização dos favos mostrou-se eficiente no controle de lagartas, atingindo níveis iguais ou superiores a 85\% de mortalidade quando foram utilizados 5 g/100 mL de água. Na aplicação por imersão dos favos, todas as dosagens testadas foram eficientes atingindo até $100 \%$ de mortalidade. Adicionada à dieta artificial, a concentração com maior porcentagem de mortalidade foi de $10 \mathrm{~g} / 60 \mathrm{~g}$ de dieta. Sintomas de infecção pelo B. thuringiensis foram identificados nas lagartas e o isolamento da bactéria, por meio de uma cultura de Bacillus, comprovou a causa da morte desses insetos em todas as dosagens da formulação comercial do B. thuringiensis var. kurstaki utilizadas.
\end{abstract}

TERMOS PARA INDEXAÇÃO: Traça da cera, controle biológico, abelha.

\begin{abstract}
This research aim at evaluating the efficiency of Bacillus thruringiensis var. kurstaki (Berliner) in the control of Galleria mellonella (Linnaeus).The experiments were conducted in the Insect Biology Laboratory of the Entomology Department of the Universidade Federal de Lavras - UFLA, Lavras, MG, Brazil, at $28 \pm 2^{\circ} \mathrm{C}$, RH $70 \pm 10 \%$ and 12 -hour photophase. Commercial formulation of B. thuringiensis. var. kurstaki was applied through spraying, comb soaking and also incorporated into the artificial diet fed to third instar caterpillars of the greater wax moth. Application of $B$. thuringiensis var. kurstaki through the spraying of the combs was efficient for control, reaching levels equal or larger than $85 \%$ of mortality when $5 \mathrm{~g} / 100 \mathrm{~mL}$ of water were utilized. In the application by soaking of the combs all the dosages tested were efficient reaching up to $100 \%$ of mortality. Added to the artificial diet, the concentration with the greatest percentage of mortality was of $10 \mathrm{~g} / 60 \mathrm{~g}$ of diet. Symptoms of infection by $B$. thruringiensis were identified both in the caterpillars and the isolation of the bacterium through a culture of Bacillus, proved to be the responsible of mortality of those insects at all the dosages of commercial formulation of $B$. thuringiensis var. kurstaki utilized.
\end{abstract}

INDEX TERMS: Greater wax moth, biological control, bee.

(Recebido para publicação em 11 de setembro de 2003 e aprovado em 24 de novembro de 2004)

\section{INTRODUÇÃO}

Os himenópteros da família Apidae são insetos que se destacam pela produção de mel, própolis, pólen, geléia real, veneno, cera e polinização, contribuindo para o aumento da produção de frutas e sementes (ALMEIDA, 2002). O Brasil possui grande potencial apícola, especialmente em função de sua extensa área territorial e diversidade de plantas nectaríferas e poliníferas. O mercado brasileiro dos produtos apícolas está avaliado atualmente em 360 milhões de dólares anuais e com potencial, em curto prazo, de chegar a um bilhão. A estimativa anual para produção de mel é de 40 mil tone- ladas, sendo a tonelada avaliada em até 2500 dólares pelo mercado internacional (KISS, 2002).

As abelhas produzem cera para construção dos favos, armazenamento de pólen e de mel, e para a construção de local para desenvolvimento de ovos, larvas e pupas. Para o armazenamento dos favos de cera, durante a entressafra, é necessária a utilização de técnicas de conservação para se evitar o aparecimento da traça Galleria mellonella (Linnaeus, 1758) (Lepidoptera: Pyralidae). As lagartas desta espécie fazem galerias nos favos, alimentando-se de cera, pólen e mel, podendo destruí-los totalmente, impedindo sua reutilização (VANDENBERG e SHIMANUKI, 1990).

1. Zootecnista, M.Sc., Doutorando em Entomologia - Universidade Federal de Lavras/UFLA, Caixa Postal 3037, 37.200-000, Lavras, MG - abelha@ufla.br

2. Professores do Departamento de Entomologia/UFLA.

3. Matemática, M. Sc., Doutoranda em Estatística e Experimentação Agropecuária/UFLA. 
Os prejuízos causados pela traça da cera têm incentivado os pesquisadores a buscarem métodos alternativos de controle, uma vez que a utilização de produtos químicos nas colméias e em favos armazenados, pode provocar a mortalidade de abelhas, contaminação do mel e demais produtos apícolas (VERMA, 1995). O controle químico já foi aplicado utilizando-se os produtos paradiclorobenzeno, ácido cianídrico, brometo de metila, sulfureto de carbono, anidrido sulfuroso e fosfina. Embora esses compostos tenham sido utilizados para o controle desse piralídeo, seu emprego apresenta inúmeros problemas, podendo-se destacar as intoxicações das abelhas nas diversas fases do seu desenvolvimento e também a contaminação do mel, cera, própolis, pólen e geléia real (BOLLHALDER, 1999).

A prevenção da traça pode ser feita por métodos físicos, sem riscos para a saúde e sem deixar qualquer espécie de resíduo. A conservação dos favos em câmaras frias apresenta ótimos resultados; contudo, é um processo caro (CHARRIÈRE e IMDORF, 1999). O método que tem proporcionado os melhores resultados no controle da traça da cera, apesar do aumento de mão-deobra, é o emprego do Bacillus thuringiensis var. kurstaki (Berliner, 1915) por meio da pulverização dos favos (VERMA, 1995).

O B. thuringiensis é uma bactéria de solo GRAm-positiva que, após a fase acelerada de crescimento, passa por um processo de esporulação devido à exaustão de nutrientes, produzindo um esporângio que contém um endosporo e inclusões cristalinas de proteínas que são responsáveis por sua ação entomopatogênica. Esse cristal protéico é composto por um polipeptídeo denominado $\delta$-endotoxina. Quando formas larvais de um inseto alimentam-se dessas proteínas, inicia-se uma série de reações que culminam com a morte das mesmas, caracterizando, assim, o efeito do controle biológico. Dessa forma, a proteína usada como bioinseticida tem participação importante em programas de controle biológico, pois não possui nenhum grau de toxicidade conhecida para os seres humanos e o ecossistema em geral (MENDONÇA, 2002).

No Brasil, o bioinseticida à base de $B$. thuringiensis var. kurstaki mais utilizado pode ser encontrado na formulação pó molhável (PM), com uma concentração de 32 g/kg (16.000 unidades internacionais de potência por mg, contendo um mínimo de 25 bilhões de esporos viáveis por grama). É um inseticida biológico de ocorrência natural, atuando por ingestão e enquadrado na classe toxicológica IV (pouco tóxico) (ANDREI, 1999).
Verma (1995) utilizou uma formulação comercial de B. thuringiensis. var. kurstaki em Uttar Pradesh na Índia, em colônias de Apis cerana (Fabricius, 1793), infestadas artificialmente com G. mellonella. A mortalidade média foi de 98,7\% das traças, quando se aplicaram $10 \mathrm{~g}$ do produto comercial por litro de água, em pulverização, e sua eficácia no controle desse inseto perdurou por 5,5 meses, sendo que as larvas das abelhas não foram afetadas.

Levando-se em consideração a importância que representa a traça da cera, tanto para colméias em condições de campo como também para favos que normalmente são armazenados na entressafra, o presente trabalho objetivou avaliar a eficiência do $B$. thuringiensis var. kurstaki, aplicado com diferentes metodologias, no controle da $G$. mellonella em favos de Apis mellifera Linnaeus 1758.

\section{MATERIAL E MÉTODOS}

Os adultos de G. mellonella foram obtidos da criação do Laboratório de Biologia de Insetos do Departamento de Entomologia da UFLA, sendo mantidos a $28 \pm 2^{\circ} \mathrm{C}$, UR $70 \pm 10 \%$ e fotofase de 12 horas. Foram acondicionados em gaiolas acrílicas, com $20 \mathrm{~cm}$ de largura por $20 \mathrm{~cm}$ de comprimento e $30 \mathrm{~cm}$ de altura, contendo internamente, uma tira retangular de papel, de $2 \mathrm{~cm}$ de largura por $20 \mathrm{~cm}$ de comprimento, dobrado em cada lateral, onde as fêmeas realizaram postura. Os ovos coletados foram colocados em recipientes de alumínio de $10 \mathrm{~cm}$ de altura por $20 \mathrm{~cm}$ de diâmetro, juntamente com favo de cera com cerca de 60 g, que foi obtido do apiário experimental da UFLA. Após a eclosão, as lagartas foram alimentadas com dieta artificial, preparada conforme metodologia proposta por Guerra (1973), composta de $94 \mathrm{~g}$ de lêvedo de cerveja, 80,2 g de farinha de soja, 192,6 g de fubá, 48,2 g de leite em pó desnatado, $236 \mathrm{~mL}$ de mel, $208 \mathrm{~mL}$ de glicerina e água destilada (cerca de $20 \mathrm{~mL}$ ).

Os insetos obtidos a partir dessa criação de $G$. mellonella foram usados para avaliar a eficiência da formulação comercial do B. var. kurstaki (Dipel ${ }^{\circledR} 32$ PM) no controle de lagartas de G. mellonella aplicado através de três metodologias:

Pulverização em favos - Suspensões de $B$. thuringiensis var. kurstaki foram preparadas nas concentrações de 0,$25 ; 0,5 ; 1,0 ; 2,5 ; 5,0 ; 10,0$ e 20,0 g por $100 \mathrm{~mL}$ de água. Foram utilizados recipientes de alumínio de $10 \mathrm{~cm}$ de altura por $20 \mathrm{~cm}$ de diâmetro, contendo um favo de $10 \mathrm{~cm}$ de comprimento e $10 \mathrm{~cm}$ de largura de aproximadamente $60 \mathrm{~g}$. O produto foi diluído em 
$100 \mathrm{~mL}$ de água destilada, homogeneizado e colocado em pulverizador manual com capacidade para $1000 \mathrm{~mL}$ e, em seguida, os favos foram pulverizados até o ponto de escorrimento, quando foram colocados nos recipientes de alumínio e transferidos para sala climatizada como descrito anteriormente. Após 12 horas, introduziram-se 10 lagartas de terceiro ínstar em cada favo que constituiu o alimento dessas até a fase de pupa. O tratamento testemunha foi constituído somente de água.

Imersão dos favos - Utilizou-se metodologia semelhante à descrita anteriormente, sendo o B. thuringiensis var. kurstaki diluído em água destilada, homogeneizado e colocado em recipiente de alumínio de $10 \mathrm{~cm}$ de altura por $20 \mathrm{~cm}$ de diâmetro. A quantidade de água utilizada no preparo da suspensão foi de 200 mL, para permitir a imersão dos favos. Estes foram imersos nas respectivas suspensões durante cinco segundos; eliminado o excesso da calda por escorrimento, sendo posteriormente colocados em recipientes de alumínio limpos e transferidos para uma sala climatizada nas mesmas condições de temperatura, umidade relativa e fotofase. Após 12 horas, introduziram-se 10 lagartas de terceiro ínstar em cada favo que constituiu a dieta alimentar ao longo de todo seu desenvolvimento. $\mathrm{O}$ tratamento testemunha foi constituído somente de água.

Adição à dieta artificial - As mesmas concentrações do B. thuringiensis var. kurstaki empregadas nos dois experimentos anteriores foram preparadas e adicionadas à dieta artificial. Foram utilizados recipientes de alumínio de $10 \mathrm{~cm}$ de altura por $20 \mathrm{~cm}$ de diâmetro, contendo 60 g de dieta artificial preparada conforme metodologia proposta por Guerra (1973), sendo adicionada à respectiva dieta a dose do B. thuringiensis var. kurstaki, seguida de homogeneização. Em cada parcela inocularam-se 10 lagartas de terceiro ínstar e as unidades experimentais foram transferidas para uma sala nas mesmas condições climáticas empregadas nos ensaios anteriores. $\mathrm{O}$ tratamento testemunha foi constituído somente de dieta artificial.

Nos três ensaios utilizaram-se delineamentos inteiramente ao acaso, com oito tratamentos e dez repetições. Fez-se o acompanhamento do desenvolvimento das lagartas até a emergência dos adultos, avaliando-se a mortalidade em cada tratamento, a qual foi corrigida utilizando a fórmula de Abbott (1925). Aplicou-se teste de médias de agrupamento de Scott e Knott (1974) $(\mathrm{P}<0,05)$. Determinaram-se por análise de Probit, curvas de concentração-mortalidade para os três bioensaios, e por meio destas, estimou-se os valores de $\mathrm{CL}_{50}$ e CL $\mathrm{CL}_{90}$ (FINNEY, 1971). O teste $\chi^{2}$ foi usado para medir o ajuste dos pontos da reta probítica.

Lagartas mortas com sintomas de doença foram retiradas de cada experimento, colocadas em placas de Petri e armazenadas em freezer $\mathrm{a}-18^{\circ} \mathrm{C}$. Posteriormente, foram transferidas para o Laboratório de Bacteriologia do Departamento de Fitopatologia da UFLA, para isolamento da bactéria e confirmação desta infecção como o fator de mortalidade das lagartas.

O isolamento de $B$. thuringiensis var kurstaki das lagartas foi realizado conforme metodologia proposta por Chaves et al. (1973) ${ }^{1}$, citados por Zanuncio (1976). Em câmara de fluxo laminar adicionou-se uma placa de Petri contendo uma alíquota de cinco lagartas de cada tratamento, inclusive da testemunha. Acrescentou-se álcool a 70\% até a completa imersão das lagartas por 30 segundos, quando foram transportadas com pinça para outra placa com solução de hipoclorito de sódio 2\% por 5 minutos. Após esse período, foram novamente colocadas em outra placa com água destilada, para retirar o excesso de hipoclorito de sódio, sendo, em seguida, maceradas e colocadas em tubos de vidro de $2,5 \mathrm{~cm}$ de diâmetro por $8 \mathrm{~cm}$ de altura.

Para eliminação de possíveis organismos saprófitos, os tubos de vidro foram colocados em banho-maria a $80^{\circ} \mathrm{C}$ por 20 minutos, uma vez que as bactérias do gênero Bacillus são resistentes a maiores temperaturas. Em seguida, foram feitas duas placas por tratamento (repicagens) para meio de cultura (Meio Básico I) composto de $10 \mathrm{~g}$ de sacarose, $4 \mathrm{~g}$ de extrato de lêvedo, $8 \mathrm{~g}$ de caseína ácida hidrolisada, 2 g de $\mathrm{K}_{2} \mathrm{HPO}_{4}$ (anidro), 0,3 g de $\mathrm{MgSO}_{4}, 20 \mathrm{~g}$ de agar e $1000 \mathrm{~mL}$ de água destilada. (KADO e HESKETT, 1970).

Ao término, as placas foram levadas para câmara climatizada em ausência de luz, regulada a $30 \pm 2{ }^{\circ} \mathrm{C}$ por 24 horas, período suficiente para o crescimento da cultura de B. thuringiensis var. kurstaki. O produto comercial também foi diluído em água esterilizada e transferido para tubo de vidro. Em seguida, foram feitas as repicagens para o meio de cultura MBI para caracterização da cultura e realizada a comparação das culturas nas placas.

\section{RESULTADOS E DISCUSSÃO}

Pulverização em favos - Em função do aumento das doses do $B$. thuringiensis. var. kurstaki, ocorreram aumentos de mortalidade, sendo que a 5,0; 10,0; e 20,0 g/ $100 \mathrm{~mL}$, esse produto provocou os maiores valores com médias de 87,8 82,9 e 84,2\%, respectivamente. Nas dosagens de 1,0 e 2,5 g/100 mL de água apresentou toxicidade intermediária com médias de 47,6 e 54,9\%, respectivamente, e nas duas menores dosagens, a mortalidade corrigida foi inferior a 29,3\% (Tabela 1).

${ }^{1}$ CHAVES, G.; CARVAlhO, M. G.; CRUZ-FILHO, J.; ROMEIRO, R. S. Roteiro de aulas de fotopatologia. Viçosa: Imprensa Universitária, 1973. 58p. 
TABELA 1 - Mortalidade (\%) ( \pm EP) ${ }^{1}$ de lagartas de terceiro ínstar de Galleria mellonella em função de diferentes concentrações do Bacillus thuringiensis var. kurstaki pulverizadas nos favos. Temperatura de $28 \pm 2^{\circ} \mathrm{C}, \mathrm{UR} 70 \pm 10 \%$ e fotofase de 12 horas. UFLA, Lavras-MG, 2003.

\begin{tabular}{ccc}
\hline $\begin{array}{c}\text { B. thuringiensis var. } \text { kurstaki } \\
\text { (g/100 } \mathbf{~} \mathbf{L} \text { de água) }\end{array}$ & Mortalidade (\%) & ${\text { Mortalidade corrigida (\%) }{ }^{\mathbf{2}}}$ \\
\hline 0,00 & $18,0 \pm 0,5 \mathrm{a}$ & 0,0 \\
0,25 & $35,0 \pm 0,7 \mathrm{~b}$ & 20,7 \\
0,50 & $42,0 \pm 0,5 \mathrm{~b}$ & 29,3 \\
1,00 & $58,0 \pm 0,5 \mathrm{c}$ & 47,6 \\
2,50 & $73,0 \pm 0,4 \mathrm{c}$ & 54,9 \\
5,00 & $90,0 \pm 0,4 \mathrm{~d}$ & 87,8 \\
10,0 & $86,0 \pm 0,5 \mathrm{~d}$ & 82,9 \\
20,0 & $87,0 \pm 0,5 \mathrm{~d}$ & 84,2 \\
\hline C.V. ${ }^{3}(\%)$ & 12,6 & - \\
\hline
\end{tabular}

Médias seguidas de mesma letra, não diferem significativamente entre si, pelo teste de Scott-Knott a 5\% de significância.

${ }^{1}$ Erro Padrão.

${ }^{2}$ Mortalidade corrigida pela fórmula de Abbott (1925).

${ }^{3}$ Coeficiente de Variação.

Observou-se a existência de um efeito crescente das concentrações do B. thuringiensis var. kurstaki na mortalidade das lagartas da traça da cera, sendo que os dados ajustaram-se ao modelo Probit (FINNEY, 1971) determinado pela equação:

Probabilidade de mortalidade $=\frac{1}{\sqrt{2 \pi}} \int_{-\infty}^{\hat{y}} \exp \left[-\frac{x^{2}}{2}\right] d x$ em que: $\hat{y}=[(-0,0644+1,0754 * \log ($ concentração) $]$

Verificou-se que nas concentrações de $1,148 \mathrm{~g}$ (IC $95 \%$ [0,834;1,506]) e 17,846 g (IC $95 \%$ [11,838; $31,362]$ ) do B. thuringienis var. kurstaki/100 $\mathrm{mL}$ de água ocorreram $50 \%$ e $90 \%$ de mortalidade de lagartas de G. mellonella, respectivamente (Figura 1).

Imersão dos favos - Verificou-se que não ocorreram diferenças significativas entre as concentrações avaliadas a 5\% de significância. A mortalidade corrigida para as dosagens do B. thuringiensis. var. kurstaki variou de 85,2 a
$100,0 \%$, sendo que todas as concentrações testadas foram tóxicas para lagartas da traça da cera (Tabela 2).

Adição à dieta artificial - A mortalidade das lagartas foi afetada significativamente pela adição do $B$. thuringiensis var. kurstaki à dieta artificial, observandose crescente aumento do número de lagartas mortas em razão do incremento das dosagens utilizadas, com mortalidades variando de 8,8 a $85,7 \%$. A testemunha diferiu de todos os tratamentos (Tabela 3).

A mortalidade causada pelo $B$. thuringiensis var. kurstaki foi agrupada em três classes distintas. Nas dosagens de 0,25; 0,5 e 1,0 g/100 mL causou mortalidade entre 8,8 e $31,9 \%$. Na segunda classe registraram-se valores de 42,9 e $56 \%$, respectivamente, para as dosagens de 2,5 e $5,0 \mathrm{~g}$ do produto. No terceiro caso, verificaramse mortalidade de 83,8 e $85,7 \%$, para 10,0 e 20,0 g do produto, respectivamente, sendo as mais tóxicas às lagartas de G. mellonella. 


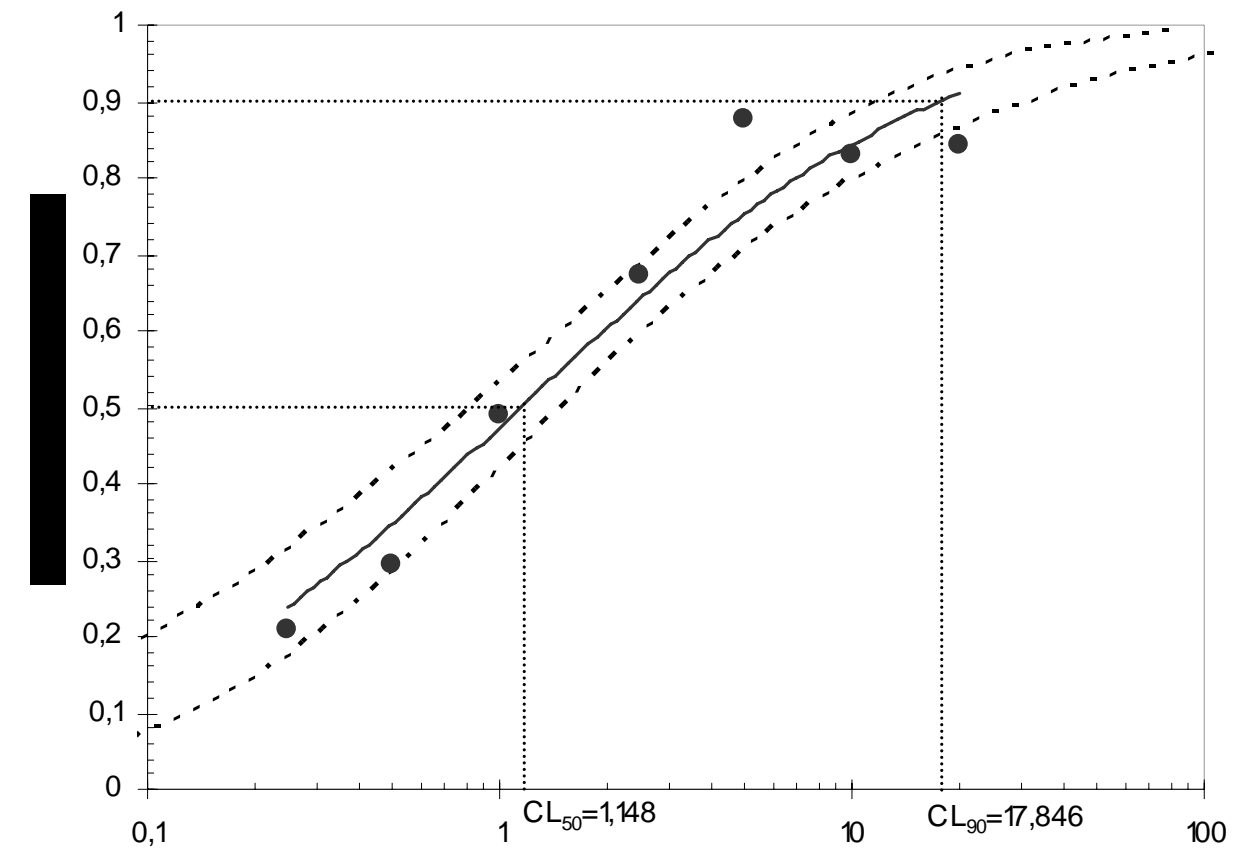

Concentração de Bacillus thuringiensis var. kurstaki (g/100 mL de água)

FIGURA 1 - Curva de concentração-mortalidade do Bacillus thuringiensis var. kurstaki pulverizado em favos para lagartas de terceiro ínstar de Galleria mellonella.

TABELA 2 - Mortalidade (\%) ( \pm EP $)^{1}$ de lagartas de terceiro ínstar de Galleria mellonella em função de diferentes concentrações do Bacillus thuringiensis var. kurstaki aplicado por imersão dos favos. Temperatura $28 \pm 2^{\circ} \mathrm{C}$, UR $70 \pm 10 \%$ e fotofase 12 horas. UFLA, Lavras-MG, 2003.

\begin{tabular}{ccc}
\hline $\begin{array}{c}\text { B. thuringiensis var. kurstaki } \\
\text { (g/100 mL de água) }\end{array}$ & Mortalidade (\%) & Mortalidade corrigida (\%) $^{2}$ \\
\hline 0,00 & $19,0 \pm 0,5 \mathrm{a}$ & 0,0 \\
0,25 & $88,0 \pm 0,6 \mathrm{~b}$ & 85,2 \\
0,50 & $99,0 \pm 0,1 \mathrm{~b}$ & 98,8 \\
1,00 & $97,0 \pm 0,2 \mathrm{~b}$ & 96,3 \\
2,50 & $100,0 \pm 0,0 \mathrm{~b}$ & 100,0 \\
5,00 & $93,0 \pm 0,2 \mathrm{~b}$ & 91,4 \\
10,0 & $98,0 \pm 0,1 \mathrm{~b}$ & 97,5 \\
20,0 & $91,0 \pm 0,3 \mathrm{~b}$ & 88,9 \\
\hline C.V. ${ }^{3}(\%)$ & 7,5 & - \\
\hline
\end{tabular}

Médias seguidas de mesma letra, não diferem significativamente entre si, pelo teste de Scott-Knott a $5 \%$ de significância.

${ }^{1}$ Erro Padrão.

${ }^{2}$ Mortalidade corrigida pela fórmula de Abbott (1925).

${ }^{3}$ Coeficiente de Variação.

Ciênc. agrotec., Lavras, v. 29, n. 1, p. 60-68, jan./fev. 2005 
TABELA 3 - Mortalidade (\%) $( \pm \text { EP })^{1}$ de lagartas de terceiro ínstar de Galleria mellonella em função de diferentes concentrações do Bacillus thuringiensis var kurstaki adicionadas à dieta artificial. Temperatura de $28 \pm 2{ }^{\circ} \mathrm{C}$, UR $70 \pm 10 \%$ e fotofase de 12 horas. UFLA, Lavras-MG, 2003.

\begin{tabular}{ccc}
\hline $\begin{array}{c}\text { B. thuringiensis var. } \text { kurstaki } \\
\text { (g/60g de dieta) }\end{array}$ & Mortalidade (\%) & Mortalidade corrigida (\%) $^{\mathbf{2}}$ \\
\hline 0,00 & $16,0 \pm 0,4 \mathrm{a}$ & 0,0 \\
0,25 & $34,0 \pm 0,5 \mathrm{~b}$ & 8,8 \\
0,50 & $43,0 \pm 0,4 \mathrm{~b}$ & 17,6 \\
1,00 & $48,0 \pm 0,7 \mathrm{~b}$ & 31,9 \\
2,50 & $61,0 \pm 0,8 \mathrm{c}$ & 42,9 \\
5,00 & $76,0 \pm 0,6 \mathrm{c}$ & 56,0 \\
10,0 & $94,0 \pm 0,3 \mathrm{~d}$ & 83,8 \\
20,0 & $95,0 \pm 0,3 \mathrm{~d}$ & 85,7 \\
\hline C.V. 3 (\%) & 14,7 & - \\
\hline
\end{tabular}

Médias seguidas de mesma letra, não diferem significativamente entre si, pelo teste de Scott-Knott a 5\% de significância.

${ }^{1}$ Erro Padrão.

${ }^{2}$ Mortalidade corrigida pela fórmula de Abbott (1925).

${ }^{3}$ Coeficiente de Variação.

O efeito do aumento da concentração do $B$. thuringienis var. kurstaki adicionado à dieta sobre a mortalidade das lagartas foi significativo $(\mathrm{P} \leq 0,05)$, sendo que os dados se ajustaram ao modelo Probit (FINNEY, 1971), determinado pela equação:

Probabilid ade de mortalidad $\mathrm{e}=\frac{1}{\sqrt{2 \pi}} \int_{-\infty}^{\hat{y}} \exp \left[-\frac{x^{2}}{2}\right] d x$ em que: $\hat{y}=[(-0,2059+1,2952 * \log ($ concentração) $]$

Verificou-se que nas concentrações de $1,442 \mathrm{~g}$ $\left(\mathrm{IC}_{95 \%}[1,110 ; 1,815]\right)$ e 14,075 g (IC $95 \%$ [10,013; 22,183]) do B. thuringienis var. kurstaki/100 mL de água ocorreram $50 \%$ e $90 \%$ de mortalidade de lagartas de G. mellonella, respectivamente (Figura 2).

As concentrações de 0,25 e $0,5 \mathrm{~g}$ de $B$. thuringiensis var. kurstaki provocaram mortalidade superior no método de aplicação por imersão, não diferindo nas metodologias de pulverização e adição à dieta. Para 1,0 e 2,5 g do produto observaram-se diferenças significativas na mortalidade entre as três metodologias, aumentando gradativamente na imersão, pulverização e dieta, respectivamente. Na concentração de 5,0 g não houve diferença na mortalidade entre a aplicação por pulverização e imersão, mas foi maior nessas do que na dieta. Quando foram utilizados 10,0 e 20,0 g do produto não ocorreram diferenças significativas nas mortalidades ocorridas entre as três metodologias de aplicação (Tabela 4).

A mortalidade ocorrida, quando utilizada a metodologia por imersão dos favos, foi maior do que nas demais formas de aplicação. Nessa metodologia, houve maior contato do favo com o produto ocasionando mortalidade superior a ocorrida na pulverização e dieta artificial, independente da concentração utilizada.

Em relação à dieta artificial, a baixa mortalidade pode estar relacionada ao fato da adição do inseticida ter alterado algumas propriedades organolépticas, causando rejeição ao alimento, principalmente quando em concentrações mais elevadas.

São praticamente inexistentes os estudos do efeito do $B$. thuringiensis var. kurstaki sobre lagartas G. mellonella por meio de adição à dieta artificial e imersão, ressaltando-se o estudo realizado por Verma (1995), através da pulverização de favos. Outros têm evidenciado a bioatividade do B. thuringiensis para $G$. mellonella como Singh (1962), Bailey (1981), Szabo e Heikel (1987) e Oirsa (1988), contudo, não foi utilizada a mesma variedade dessa bactéria. 


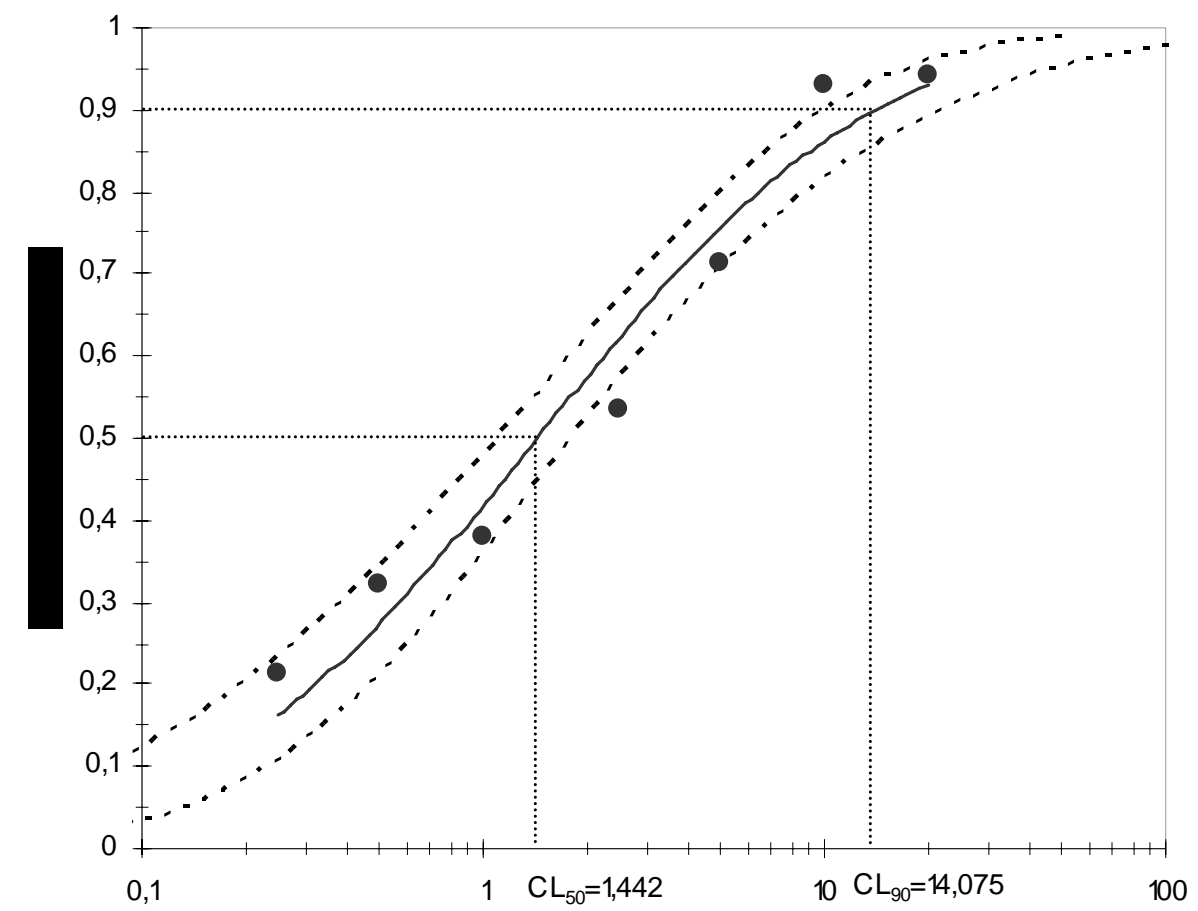

Concentração de Bacillus thuringiensis var. kurstaki (g/60 g de dieta artificial)

FIGURA 2 - Curva de concentração-mortalidade do Bacillus thuringiensis var. kurstaki adicionado à dieta artificial para lagartas de terceiro ínstar de Galleria mellonella.

TABELA 4 - Mortalidade (\%) $( \pm \text { EP })^{1}$ de lagartas de terceiro ínstar de Galleria mellonella em função de diferentes métodos de aplicação de Bacillus thuringiensis var kurstaki.Temperatura de $28 \pm 2{ }^{\circ} \mathrm{C}$, UR $70 \pm 10 \%$ e fotofase de 12 horas. UFLA, Lavras-MG, 2003.

\begin{tabular}{cccc}
\hline B. thuringienis. var. kurstaki (g) & \multicolumn{3}{c}{ Método de aplicação/ Mortalidade (\%) } \\
\cline { 2 - 4 } & Pulverização & Imersão & Dieta \\
\hline 0,00 & $18,0 \pm 0,5 \mathrm{aA}$ & $19,0 \pm 0,5 \mathrm{aA}$ & $16,0 \pm 0,4 \mathrm{aA}$ \\
0,25 & $35,0 \pm 0,7 \mathrm{bA}$ & $88,0 \pm 0,6 \mathrm{bB}$ & $34,0 \pm 0,5 \mathrm{bA}$ \\
0,50 & $42,0 \pm 0,5 \mathrm{bA}$ & $99,0 \pm 0,1 \mathrm{bB}$ & $43,0 \pm 0,4 \mathrm{bA}$ \\
1,00 & $58,0 \pm 0,5 \mathrm{cB}$ & $97,0 \pm 0,2 \mathrm{bC}$ & $48,0 \pm 0,7 \mathrm{bA}$ \\
2,50 & $73,0 \pm 0,4 \mathrm{cB}$ & $100,0 \pm 0,0 \mathrm{bC}$ & $61,0 \pm 0,8 \mathrm{cA}$ \\
5,00 & $90,0 \pm 0,4 \mathrm{~dB}$ & $93,0 \pm 0,2 \mathrm{bB}$ & $76,0 \pm 0,6 \mathrm{cA}$ \\
10,0 & $86,0 \pm 0,5 \mathrm{dA}$ & $98,0 \pm 0,1 \mathrm{bA}$ & $94,0 \pm 0,3 \mathrm{dA}$ \\
20,0 & $87,0 \pm 0,5 \mathrm{dA}$ & $91,0 \pm 0,3 \mathrm{bA}$ & $95,0 \pm 0,3 \mathrm{dA}$ \\
\hline
\end{tabular}

Médias seguidas pela mesma letra minúscula, nas colunas, e maiúscula, nas linhas, não diferem significativamente entre si, pelo teste de Scott-Knott a 5\% de significância.

${ }^{1}$ Erro Padrão.

Ciênc. agrotec., Lavras, v. 29, n. 1, p. 60-68, jan./fev. 2005 
No presente trabalho obteve-se mortalidade de $86 \%$ utilizando $10 \mathrm{~g}$ do $B$. thuringiensis var. kurstaki/100 $\mathrm{mL}$ de água pulverizado em favos de $A$. mellifera, sendo que Verma (1995) obteve 98,7\% de mortalidade das lagartas com a mesma concentração do produto.

Das três formas de aplicação, a pulverização seria aconselhável apenas para os apicultores de pequeno porte; para apicultores de grande porte o manejo dos favos, que devem ser pulverizados em ambas as faces, dificultaria a implantação da metodologia. A imersão é a mais prática pela facilidade de aplicação do produto, em que os favos são mergulhados inteiramente na suspensão, reduzindo a mão-de-obra e tempo de execução, sendo a metodologia apropriada para qualquer tipo de apicultor.

Sintomas de infecção nas lagartas de $G$. mellonella pela ação do B. thuringiensis var. kurstaki foram observados em todas as metodologias de aplicação desse produto, sendo mais pronunciados nas maiores dosagens. Observou-se que nas lagartas infectadas, o tegumento perdeu o brilho, adquirindo coloração marrom-escura, diminuíram a agilidade, tornando-se flácidas e pararam de se movimentarem a partir de 48 horas do contato com o B. thuringiensis var. kurstaki, quando algumas delas abandonaram a dieta artificial. Sintomas relacionados ao abandono do alimento foram visualizados quando $B$. thuringiensis var. kurstaki foi incorporado à dieta artificial, pois tanto na imersão quanto na pulverização dos favos, as lagartas permaneceram no interior das galerias, dificultando a identificação. Logo após a morte as lagartas adquiriram sintomas externos como coloração preta iniciando-se a deterioração de seus tecidos acompanhados de odor fétido, o que já foi relatado por Habib e Andrade (1998) em lagartas do noctuídeo Alabama argillacea (Hübner, 1818) e o brassolídeo Brassolis sophorae (Linnaeus, 1758) infectadas por B. thuringiensis var. kurstaki.

$\mathrm{O}$ isolamento pelo MBI nas lagartas dos três experimentos, após 24 horas, evidenciou a presença do $B$. thuringiensis var. kurstaki mediante o do crescimento de cultura nas placas de Petri, não excluindo a causa da mortalidade por essa bactéria. Os isolados apresentaram colônias de 3 a 5 mm de diâmetro, formato circular, borda ondulada, superfície granulosa, opaca, branca e de consistência úmida. Os resultados para os isolados obtidos dos tratamentos com as diferentes dosagens foram idênticos quando comparados com isolamento da cultura do B. thuringiensis var. kurstaki feito com o produto comercial, comprovando ser o mesmo microorganismo patogênico para o grupo de lagartas dos três experimentos, diferindo apenas dos isolados obtidos com as lagartas isentas da aplicação do produto (testemunha).

Pelos resultados obtidos, pode-se inferir que a metodologia de aplicação foi um fator importante sobre a eficiência desse produto fitossanitário na mortalidade das lagartas da traça da cera. Pesquisas futuras envolvendo concentrações menores e método de aplicação devem ser desenvolvidas visando ao aprimoramento dessa técnica de controle de G. mellonella.

Evidenciou-se que G. mellonella apresentou susceptibilidade a $B$. thuringiensis. var. kurstaki. A maior ou menor porcentagem de mortalidade ocorrida nos experimentos pode estar relacionada com o método de aplicação do produto e a possibilidade da lagarta se alimentar.

Com o desenvolvimento de pesquisas para o aprimoramento das técnicas de aplicação do produto, é provável que, num futuro próximo, seja viável o emprego do $B$. thuringiensis var. kurstaki no controle da G. mellonella, especialmente em favos armazenados durante o período de escassez de mel ou quando se fizer necessária a estocagem de quadros de ninhos e melgueiras com cera.

\section{CONCLUSÕES}

a) O Bacillus thuringiensis var. kurstaki aplicado via pulverização ou imersão dos favos ou incorporado à dieta foi eficiente no controle da Galleria mellonella.

b) O método de imersão dos favos em suspensão de Bacillus thuringiensis var. kurstaki foi mais eficiente para o controle de Galleria mellonella do que a pulverização ou adição em dieta artificial.

c) Via pulverização nos favos, a CL50 foi de 1,148 g do Bacillus thuringiensis var. kurstaki/100 mL de água.

d) O Bacillus thuringiensis var. kurstaki aplicado por imersão dos favos foi eficiente para o controle de Galleria mellonella em todas as dosagens testadas, com média superior a $80 \%$ de mortalidade.

e) Via adição à dieta artificial, a $\mathrm{CL}_{50}$ foi de $1,442 \mathrm{~g}$ do Bacillus thuringiensis var. kurstaki/60 g de dieta.

\section{REFERÊNCIAS BIBLIOGRÁFICAS}

ABBOTT, W. S. A method of computing the effectiveness of an insecticide. Journal of Economic Entomology, Lanham, v. 18, p. 265-267, 1925. 
ALMEIDA, D. Espécies de abelhas (Hymenoptera, Apoidea) e tipificação dos méis por elas produzidos em área de cerrado do município de Pirassununga, Estado de São Paulo, 2002. 103 f. Dissertação (Mestrado) - Escola Superior de Agricultura Luiz de Queiroz, Piracicaba, 2002.

ANDREI, E. Compêndio de defensivos agrícolas: guia prático de produto fitossanitário para uso agrícola. São Paulo: Andrei, 1999. 672 p.

BAILEY, L. Honey bee pathology. New York: Academic, 1981. 124 p.

BOLLHALDER, F. Trichogramma for wax moth control. American Bee Journal, Hamilton, v. 139, n. 9, p. 711-712, 1999.

CHARRIÈRE, J. D.; IMDORF, A. Protecion of honey combs from wax moth damage. American Bee Journal, Switzerland, v. 139, n. 8, p. 627-630, 1999.

FINNEY, D. J. Probit analysis. 3. ed. Cambridge: Cambridge University, 1971. 333 p.

GUERRA, M. S. Bionomia das traças de cera Galleria mellonella L. e Achroia grisella F. (Lepidoptera: Galleridae) no Município de Piracicaba. 1973. 133 f. Dissertação (Mestrado em Entomologia) - Escola Superior de Agricultura Luiz de Queiroz, Universidade de São Paulo, Piracicaba, 1973.

HABIB, M. E. M.; ANDRADE, C. F. S. Bactérias entomopatogênicas. In: ALVES, S. B. (Ed.). Controle microbiano de insetos. 2. ed. Piracicaba: FEALQ, 1998. $1163 \mathrm{p}$

KADO, C. I.; HESKETT, M. G. Selective media for isolation of Agrobacterium, Corynebacterium, Erwinia, Pseudomonas and Xanthomonas. Phytopathology, Saint Paul, v. 60, p. 969-976, 1970.
KISS, J. Mel para viagem. Globo Rural, Rio de Janeiro, v. 18, n. 206, p. 30-37, 2002.

MENDONÇA, P. C. Caracterização e sequenciamento dos plasmídeos pMC1 e pMC2 de Bacillus thuringiensis var. thuringiensis isolado T01 328. 2002. 53 f. Dissertação (Mestrado em Agronomia, Genética e Melhoramento de Plantas) - Universidade do Estado de São Paulo, Jaboticabal, 2002.

OIRSA, B. Manejo y control de la abeja africanizada: programa regional para el manejo y control de la abeja africanizada. El Salvador: [s.n.], 1988. 229 p.

SCOTT, A. J.; KNOTT, M. A. A cluster analysis method for grouping means in the analysis of variance. Biometrics, Washington, v. 30, n. 3, p. 507-512, 1974.

SINGH, S. Beekeeping in India. New Delhi: Indian Council of Agricultural Research, 1962. 214 p.

SZABO, T. I.; HEIKEL, D. T. Fumigation with $\mathrm{SO}_{2}$ to control dried fruit moth in honeybee combs. Bee World, Bucks, v. 68, n. 1, p. 37-38, 1987.

VANDENBERG, J. D.; SHIMANUKI, H. Viability of Bacillus thuringiensis and its efficacy for larvae of the greater wax moth (Lepidoptera: Pyralidae) following storage of treated combs. Journal of Economic Entomology, Beltsville, v. 83, n. 3, p. 760-765, 1990.

VERMA, S. K. Studies on the control of greater wax moth, Galleria mellonella L. in Apis cerana F. colonies with the biological insecticide, Dipel. Indian Bee Journal, Nainital, v. 57, n. 3, p. 121-123, 1995.

ZANUNCIO, J. C. Efeito do controle químico e microbiológico sobre três pragas de eucalipto e outros insetos. 1976. 76 f. Dissertação (Mestrado em Entomologia) - Universidade Federal de Viçosa, Viçosa, 1976. 